\title{
A POLÍTICA EDUCACIONAL BRASILEIRA E AS DIRETRIZES DO PROGRAMA EDUCAÇÃO PARA TODOS: NOTAS CRÍTICAS
}

\author{
Deribaldo dos Santos ${ }^{1}$ \\ Maria das Dores Mendes Segundo ${ }^{2}$ \\ Maria Cleidiane Cavalcante Freitas ${ }^{3}$ \\ Tayanna Vieira Lima ${ }^{4}$
}

\section{RESUMO}

O presente artigo tem como objetivo analisar as influências das diretrizes do programa Educação para Todos (EPT), imposto pelos organismos internacionais como política educacional nos países periféricos, como o Brasil. Nestes termos, investigamos documentos e declarações impostas pelas agências multilaterais, em congressos, fóruns de EPT, a partir de 1990, para refletir a função social da educação e da escola, em meio a crise do capitalismo contemporâneo, entendida por István Mészáros, como de caráter estrutural. Tomando como base a perspectiva de formação omnilateral, prescrita por Karl Marx, compreendemos que as determinações e o monitoramento dos organismos internacionais por meio de políticas educacionais nos países pobres, atrelam ao ideário de uma Educação para Todos, porém se restringem à educação básica, como a única possível à classe trabalhadora, tornando-se, desse modo, uma estratégia ideológica e econômica do capital em crise estrutural.

Palavras-chave: Educação para Todos; Crise estrutural do capital; Função social da escola.

\section{THE BRAZILIAN EDUCATIONAL POLICIES AND THE GUIDELINES OF THE EDUCATION FOR ALL PROGRAM: CRITICAL NOTES.}

\begin{abstract}
This article presents the influences of the guidelines of Education for All program (EFA), imposed by international organizations like educational policy in peripheral countries, such as Brazil. In these terms, we investigated documents and imposed declarations by the multilateral agencies, at conferences, Education For All forums, since 1990, to reflect the social function of education and school in the middle of the contemporary capitalism crisis, understood by István Mészáros as structural feature. Based on the perspective omnilateral formation, prescribed by Karl Marx, we understand that the determination and monitoring of the international organizations through educational policies in poor countries, join the ideals of Education for All, but just basic education, the only one which is possible to the working class, becoming an ideological and economic strategy in capital structural crisis. Keywords: Education for All; Capital structural crisis; Social function of the school.
\end{abstract}

\section{Introdução}

Neste estudo, objetivamos refletir sobre as influências que o ideário da chamada Educação para Todos (EPT) mantém sobre as políticas educacionais dos países pobres, em especial, do Brasil. Almejamos demonstrar que diante da crise estrutural do capital (MÉSZÁROS, 2002), os organismos internacionais, a exemplo do Banco Mundial (BM), determinam e regulam diretrizes de cunho sócio educacional para os países pobres, 
atribuindo ao complexo da educação a responsabilidade de solucionar problemas gerados fora do escopo educativo, como a pobreza, as epidemias, a violência urbana, a sustentação ambiental, dentre outras características do fenômeno da crise que passa a existir na atual quadra histórica. Perante esse cenário, as múltiplas atribuições que a educação, e respectivamente a escola, recebe para adequação às regras do capital em processo de acumulação ampliada, desviar-se do vértice de formar indivíduos em condições de compreender o mundo em que se vive.

Para nos aprofundarmos nesse debate com o devido rigor conceitual que a problemática exige, optamos por seguir o caminho aberto por Marx (2003), para quem o trabalho é o ato fundante do ser social. Conforme ratifica Lukács (2012), é por meio da categoria trabalho que os demais complexos sociais se desenvolvem, dentre os quais a educação exerce a função universal de transmissão do conhecimento acumulado pela humanidade. Na esteira de Marx, Lukács explica que o trabalho funda, mas não esgota a formação do ser social, sendo preciso, para isso, a edificação de outros complexos sociais que guardarão com o trabalho uma relação de autonomia relativa. Cabe-nos esclarecer que no contexto do capitalismo contemporâneo, o trabalho passa a assumir uma dupla função: além de ser o complexo fundante do ser social passa também a ser utilizado em favor das relações de domínio estabelecidas pela classe exploradora que se beneficia do esforço alheio, alienando radicalmente as relações de produção existentes na sociedade. Portanto, nossa opção teórico-metodológica é pela ontometodologia marxista, visto que é o suporte necessário para nos guiar na empreitada de refletir criticamente a problemática aqui estudada.

Para efeito da presente exposição, analisamos criticamente alguns documentos da chamada $\mathrm{EPT}^{5}$ expostos em várias conferências e fóruns mundiais ocorridos, anualmente, a partir de 1990. Nesses documentos, de maneira geral, encontramos a educação e por esta via, a escola como elemento principal para a garantia da governabilidade, da sustentabilidade socioeconômica e ambiental, da erradicação da pobreza e da contenção da violência urbana, mediante a propalada cultura de paz. Mas não é só: a educação sistematizada também é apresentada como caminho para se garantir emprego e ascensão das classes consideradas em vulnerabilidade social. Com efeito, por intermédio da meta primordial da Educação para Todos, que os países-membros da Organização das Nações Unidas (ONU), sobretudo os pobres, precisam universalizar a educação básica, como requisito para garantir o acesso ao chamado mundo globalizado, o complexo educativo, no nível de escolaridade primária, é apresentado pelos organismos internacionais como a estratégia capaz de extinguir todos os problemas de desigualdades produzidos pelo capitalismo em crise na sociedade. Posteriormente, com essa análise em tela e ponderando sobre as necessidades de reprodução do capital em sua atual fase de crise estrutural, como desvela o filósofo Mészáros (2002), apresentaremos algumas considerações sobre a função social da educação, em particular da escola.

\section{Educação para Todos: a adaptação do complexo educativo às demandas da nova (des)ordem mundial}

A partir das últimas décadas do século $\mathrm{XX}$, com radicalidade nos primeiros anos do atual século, a educação passa a ser vista pelos organismos internacionais, governos, empresários, discursos midiáticos, bem como por pais e vários professores, como um mecanismo capaz de solucionar os problemas socioculturais decorrentes das desigualdades econômicas, sobretudo nos países ditos periféricos. Para os defensores desse modelo, o processo educativo deveria priorizar uma formação que prepare o indivíduo para o 
mercado de trabalho, pois apenas assim é possível à educação reverter as condições de desigualdade social existente nos países pobres, bem como garantir a inserção destes no chamado mundo globalizado.

Recorremos ao filósofo húngaro István Mészáros (2002) que afirma haver no atual cenário do capitalismo contemporâneo uma crise estrutural do capital, provocada pela acentuada queda das taxas de lucros. Para esse autor, o momento atual é de crise profunda no sistema capitalista, pois, na atual crise, todas as fraturas estruturais do sistema sociometabólico do capital estão expostas, o que amplia a intensidade das desigualdades e das contradições sociais, afetando, de modo contínuo e devastador, todos os âmbitos da sociedade. Como explica Mészáros (2002, p. 796):

A novidade histórica da crise de hoje (estrutural) torna-se manifesta em quatro aspectos principais: (1) seu caráter é universal, em lugar de restrito a uma esfera particular (por exemplo, financeira ou comercial, ou afetando este ou aquele ramo particular de produção, aplicando-se a este e não àquele tipo de trabalho, com sua gama específica de habilidades e graus de produtividade etc.); (2) seu alcance é verdadeiramente global (no sentido mais literal e ameaçador do termo), em lugar de limitado a um conjunto particular de países (como foram todas as principais crises no passado); (3) sua escala de tempo é extensa, contínua, se preferir, permanente, em lugar de limitada e cíclica, como foram todas as crises anteriores do capital; (4) em contraste com as erupções e os colapsos mais espetaculares e dramáticos do passado, seu modo de se desdobrar poderia ser chamado de rastejante, desde que acrescentemos a ressalva de que nem sequer as convulsões mais veementes ou violentas poderiam ser excluídas no que se refere ao futuro: a saber, quando a complexa maquinaria agora ativamente empenhada na "administração da crise" e no "deslocamento" mais ou menos temporário das crescentes contradições perder sua energia.

Vale elucidar, com Rio (2013, p. 237), "que o capitalismo se constitui a variante histórica por excelência do capital, isto é, o modo produtivo que tem levado às últimas consequências a sede exacerbada de lucros do capital."

A lógica do capital sob a armadura do capitalismo, por ser essencialmente destrutiva, para que possa resguardar sua crise mais hodierna, subordina radicalmente o valor de uso ao valor de troca. Essa lógica faz emergir o que Mészáros (2002) chama de "taxa decrescente do valor de uso das mercadorias", cuja finalidade é reduzir a vida útil dos produtos. Essa tendência de diminuição da vida útil dos produtos é uma das estratégias principais para a expansão e acumulação de lucros (RIO, 2012). Contudo, em um quadro de crise como o que a atual quadra histórica presencia, para que o capitalismo continue garantindo o lucro para o capital, é preciso que os produtos produzidos pelo esforço humano e transformados em mercadoria pelo capitalismo contemporâneo, atendam a tendência de taxa zero de utilização das mercadorias. Isto é, para que o capital possa se tornar mais atraente, aquelas mercadorias devem ser utilizadas, no máximo, apenas uma vez. Desse modo, como muito bem conclui Rio (2012, p. 238), "o capitalismo contemporâneo aprofundou, sobremaneira, o fosso entre a produção para a satisfação das necessidades humanas e a produção para a autorreprodução do capital."

De acordo com Mészáros (2002), o capital alcançou os seus limites absolutos, mediante a intensificação da produção destrutiva. A partir de então, a dinâmica de expansão do capital torna trivial a destruição maciça das forças produtivas, através da produção da destruição, financiada pelo Estado e consubstanciada por meio do complexo 
industrial militar. Para tanto, ainda em acordo com o que escreve esse filósofo, o capital põe em curso inúmeras medidas, de ordens diversas, cujo interesse incessante é o de reformar o Estado, a fim de que este favoreça os mecanismos de exploração do capital sobre o trabalho.

Portanto, a crise do capital é marcada, sobretudo, pela tendência decrescente da taxa de lucro e a destrutividade das forças produtivas, provocando desdobramentos nos demais complexos sociais, sendo reconfiguradas sob a lógica do capital.

Nesse contexto de profunda crise estrutural do capital, a educação é chamada para assumir tamanha intervenção, uma vez que esta, desde a gênese do capitalismo, se constituía uma bandeira da classe trabalhadora. Assim sendo, as políticas públicas direcionadas ao complexo educacional, recebem uma atenção diferenciada por parte dos organismos internacionais, com vistas a uma recomposição do papel da escola. É nesse panorama que o Banco Mundial (BM), o Fundo Monetário Internacional (FMI) e a Organização das Nações Unidas para a Educação, Ciência e Cultura (Unesco), para citar apenas esses três, investem financeiramente nos países periféricos, tendo como o objetivo principal erradicar a pobreza com o auxílio da escola. Segundo Leher (2010, p. 22), o Banco Mundial "volta-se para programas que atendam diretamente as populações possivelmente sensíveis ao 'comunismo'." Esse autor acrescenta, ainda, que: "por meio de escolas técnicas, programas de saúde e controle de natalidade, ao mesmo tempo em que promove mudanças estruturais na economia desses países", também, possibilita-se determinado controle social, como meio de assegurar a governabilidade.

Ancorados nas novas exigências do mercado de trabalho, o discurso do BM impõe à educação dos países pobres, a necessidade de renovar seus métodos, currículos e propostas pedagógicas. Dessa maneira, visto que, conforme entendem os intelectuais dessas agências, as novas tecnologias demandam, cada vez mais, novas exigências da formação dos indivíduos. Caberia à escola, nesse suposto novo cenário, preparar o indivíduo para operar as novas ferramentas advindas de uma imaginária era tecnológica ${ }^{6}$, sociedade do conhecimento ${ }^{7}$, ou algo que o valha.

Dessa forma, como destaca Santos (2009, p. 2-3), "a educação é chamada a dar conta de problemas muito além de seu escopo, os quais se enraízam na própria trama de contradições do capital em crise". A lógica é totalmente invertida pelo capital, que atribui a educação, mediante a construção de novos paradigmas pedagógicos, elementos de competências a classe trabalhadora, capaz de alcançar excito no mercado de trabalho, ou seja, que a educação ofereceria "a possibilidade de criar postos de trabalho, quando, na verdade, estes vêm sendo materialmente reduzidos de modo drástico, no quadro da referida crise."(SANTOS, 2009, p. 3).

Toda essa engenharia educativa acontece por meio de ações estratégicas das agências internacionais que orientam e monitoram as políticas educacionais dos países periféricos, em conformidade com as necessidades de acumulação do capital mundial. Para usarmos mais uma vez as reflexões de Mészáros (2002), tais necessidades seriam produzidas para tentar dar conta da crise, aprofundada no final do século XX, que demanda, mais que nunca, um trabalhador minimamente e acriticamente escolarizado, todavia, proativo e consensual, que garanta, sem risco, a reprodução do sistema produtivo sob o capital.

É nessa tela histórica que o Banco Mundial dispõe de seu apoio financeiro para influenciar diretamente as diretrizes educacionais dos países periféricos. Como esclarece Leher (1999, p. 26), na década de 1970, o Banco "considerava o financiamento às escolas primárias e secundárias de formação geral um contra-senso, defendendo o ensino técnico e profissional, modalidades tidas como mais adequadas às necessidades [presumidas] dos 
países em desenvolvimento.” Ressaltamos, apoiados em Santos (2009), que no atual momento de mercantilização da educação, há uma intencionalidade das agências internacionais e de seus empresários, que os jovens trabalhadores sejam encaminhados para o ensino superior. Contudo, jamais para uma universidade pública, laica, gratuita e de qualidade. Os interesses empresariais resumem-se, em última instância, no escoamento dos trabalhadores e seus filhos para os cursos superiores aligeirados, fragmentados, sequenciais, à distância, entre outros assemelhados do conjunto que compõe o chamado ensino superior não universitário $(\mathrm{ESNU})^{8}$.

Nesse cenário, as propostas lançadas para os países pobres, entendidos pelos organismos internacionais como populações em vulnerabilidade social, chama-nos a atenção. Dentre elas destacamos, conforme acordo selado pela Conferência Mundial de Educação para Todos, ocorrida em 1990, na cidade tailandesa de Jomtien: possibilitar o acesso de todos à educação. Vale elucidar que três anos depois, a 6 de dezembro, em Nova Delhi, foi realizada uma nova conferência, resultando na Declaração de Nova Delhi sobre Educação para Todos, na qual se renovaram as crenças nos preceitos desses organismos, bem como os prazos das metas de EPT definidas no encontro da Tailândia.

O compromisso com as metas de EPT foi reafirmado no Fórum Mundial de Educação: Marco de Dacar, realizado no Senegal, no ano de 2000, bem como em outras conferências sobre a educação que se seguiram. O encontro em questão teve como objetivo principal prorrogar mais uma vez o prazo para a universalização do ensino fundamental, agora ampliado para o ano de 2015. Vejamos o que escreve o relatório da Conferência de Dacar:

Não tenho dúvida de que, aqui em Dacar, conseguiremos adotar uma estrutura de trabalho global que representará o compromisso claro e irreversível da comunidade internacional, no sentido de, até 2015, satisfazer as necessidades básicas de aprendizado de todas as crianças, jovens e adultos, independentemente de onde vivam. (UNESCO, 2000, p. 41).

Para os agentes internacionais, a educação deve assumir a função de erradicar a pobreza, promover a paz, diminuir a contaminação por doenças epidêmicas e prover a estabilidade econômica nos países pobres do globo, dentre outras determinações. Porém, a questão de vivermos numa sociedade de classes, de interesses antagônicos, na qual uns detêm os meios de produção, enquanto outros possuem somente a sua força de trabalho não é, em hipótese alguma, debatida. As concepções da agenda de EPT trazem justificativas variadas, contudo, todas sinalizam para a criação de um novo ideário educacional, para a formação de trabalhadores minimamente capacitados para acompanhar as mudanças ocorridas no setor produtivo, agora de natureza destrutiva. Esse discurso, muito bem aparelhado aos interesses do modo de exploração capitalista em crise profunda, defende que os trabalhadores ditos qualificados ficarão na condição de empregabilidade, formalizando, desse modo, o objetivo da EPT de que a educação, sobretudo, a básica, constitui a principal estratégia de formação do trabalhador e, conseqüentemente de redução das desigualdades sociais.

O Fórum de Dacar tratou da educação básica como política de qualificação dos indivíduos para o mercado de trabalho (chamado pelos intelectuais dessas agências de mundo do trabalho $)^{9}$ e apontou para o estabelecimento de novos pilares para uma suposta nova educação em o novo século. Diz o texto: 


\begin{abstract}
A educação básica demanda o mínimo de conhecimentos e habilidades para que um indivíduo seja capaz de contribuir plenamente para o seu meio ambiente local e estar no controle de sua própria vida. Num universo que se torne a cada dia mais interdependente, está evoluindo o conteúdo e, portanto, a própria idéia [Sic] da "qualidade" da educação básica. Já não se pode mais reduzi-la a "ler, escrever, fazer contas". Ela, também, tem de ensinar as pessoas a ser, a fazer, a aprender e a viver juntas. (FÓRUM DE DACAR, 2000, p. 51).
\end{abstract}

Esse documento expõe a finalidade da EPT: defender a aprendizagem mínima, necessária para o desenvolvimento de competências e habilidades para o exercício imediato de um ofício. Com efeito, cabe a escola comportar mecanismos de ensino e aprendizagem, de cunho competitivo e empresarial. A partir desses pressupostos, o ensino escolar não precisaria se preocupar com a apropriação dos conhecimentos universalmente produzidos pelo homem no seu processo civilizatório, a exemplo da matemática, a linguagem, a arte, as ciências naturais e sociais, enfim, legaliza a proibição de ensinar conteúdos que elevem a erudição dos educandos, e que lhes garantam a apropriação histórica do que a humanidade produziu. O que realmente interessa ao mercado, é capacitar um novo trabalhador que se aproprie de paradigmas educacionais voltados, exclusivamente para construção de valores e as atitudes favoráveis às atividades laborais.

Essas premissas são ratificadas anos mais tarde no relatório para a Unesco, elaborado pela Comissão Internacional sobre Educação para o Século XXI, o qual propaga os chamados quatro pilares da educação, cujo título é Educação: um Tesouro a Descobrir. Esse documento foi produzido seis anos depois do evento de Jomtien e publicado no Brasil em 1998; redigido pelo teórico francês Jacques Delors, o que o levou a ser comumente chamado de Relatório Delors. O texto desse documento versa principalmente sobre o que seria a base para uma educação em acordo com a nova ordem sociopolítica e econômica, designada pelo relatório em quatro pilares: 1) aprender a conhecer; 2) aprender a fazer; 3) aprender a viver; e 4) aprender a ser, posteriormente foi agregado o paradigma do aprender a empreender.

Baseado numa visão de mundo em que vivenciamos numa inédita "sociedade do conhecimento", essas concepções defendem a idéia de que se faz necessário, o individuo dominar as inovações tecnológicas para poder ser inserido nessa sociedade dita engenhosa. Desse modo, a classe trabalhadora precisa adquirir qualificação e competência para serem incluídos no mercado de trabalho que demanda mudanças e evoluções constantes desse novo trabalhador, sem necessariamente ter que absorver os conteúdos clássicos produzidos ao longo da história. O mais importante, no atual processo de formação para o trabalho é aprender a conviver com outros e, ao mesmo tempo, "vestir a camisa da empresa". Sintetizando, a formação do novo trabalhador tem como premissa em transformá-los em pessoas pacíficas, que convivam como cidadãos de bem, em defesa de sociedade que estimula o individualismo e a competitividade ${ }^{10}$.

Fica evidente, portanto, que esses elementos constituiriam a essência e a existência do homem contemporâneo circunscrito na lógica de mercado. O paradigma do aprender a aprender que restringe o conhecimento a "saberes" úteis e necessários a uma sociedade apregoada como planetária, molda um novo modelo de homem capaz de se responsabilizar pelas próprias crises do capital, tornando-se um importante instrumento econômico e ideológico no processo de reversão da queda das taxas de lucros.

As "pedagogias do aprender a aprender", assim denominadas por Duarte (2001), são teorias centradas nos posicionamentos valorativos, em que as aprendizagens que os indivíduos realizam por si mesmo, são mais significativas e ricas do que os conhecimentos 
e experiências transmitidos por outros indivíduos. Nessa perspectiva aprender sozinho contribuiria para autonomia e a formação de indivíduos criativos.

Ainda segundo Duarte (2001, p. 38), o importante atentar, no entanto, para um detalhe fundamental: "essa criatividade não deve ser confundida com busca de transformações radicais na realidade social". Essa proposta pedagógica, assim como suas congêneres, nascidas da necessidade de recomposição das perdas do capital em crise, jamais podem proporcionar algum tipo de criatividade autêntica que, no limite máximo, potencializa o sujeito para se adaptar às intermitências capitalistas. Por essa exposição de motivos, preferimos denominá-la de "aprender a (des)conhecer", visto que seus fundamentos pedagógicos não favorecem o conhecimento e, tampouco, ambicionam formar o homem para a plenitude humana; limita, desse modo, a interesses imediatos que pleiteiam o educando a desconhecer a verdade. A verdade, com efeito, como lembrava Lênin, será sempre revolucionária.

Em linhas gerais, afirmamos que a proposta pedagógica do "aprender a (des)conhecer" aparece no universo escolar com o objetivo de favorecer o aligeiramento, a fragmentação, a flexibilização, a polivalência, entre algumas outras necessidades capitalistas para formatar o trabalhador para uma sociedade do (des)conhecimento. Para as vicissitudes de um capitalismo em crise profunda, interessa ao capital encobrir a verdade, ou seja, negar o conhecimento à classe trabalhado, oferecendo uma educação pautada no mínimo de conteúdo, que priorize o desconhecimento do real, distanciando, sobremaneira, a plena formação dos trabalhadores em sua plenitude (conhecer o mais aproximadamente possível o real). Portanto, como muito bem reflete Braverman (1987, p. 372), no processo produtivo, quanto mais é preciso dotar o trabalhador de saber, menos ele está apto a conhecer; "nas escolas que as massas de futuros trabalhadores frequentam quanto mais há para aprender, tanto menos razão há para os professores ensinarem e para os alunos aprenderem."

\section{Educação para imediatismo e para a superficialidade}

Compreendido o liame da questão, retomemos a relação entre os agentes econômicos internacionais e a educação dos países periféricos, destacando o caso do Brasil. De acordo com Jimenez e Mendes Segundo (2007, p. 124), “impõem-se mudanças devastadoras [às nações signatárias], aplicando-se aos padrões de financiamento e à forma de gestão dos sistemas de ensino, como as definições curriculares, os processos avaliativos e os modelos de formação docente", caráter estritamente empresarial e mercadológico. O Banco Mundial "cobrará, então, do país tomador de seus empréstimos, uma declaração de compromisso com o desenvolvimento econômico e com aceitação do monitoramento na definição de suas políticas setoriais."

Para Rabelo, Mendes Segundo e Jimenez (2009) a situação entre os sujeitos sociais em condição de precariedade ao acesso à educação de qualidade, são mescladas por teorias de cunho economicista, impostas pelos organismos transnacionais que, em vez de garantir, ou ao menos apontar para uma formação escolar condigna para a transformação da sociedade, acenam com políticas educativas restritivas. Dessa forma, em nome da adequação às demandas do mercado, são apresentadas concepções pedagógicas utilitaristas, instrumentais e neopragmáticas. Como observam as referidas autoras, operase, nesse contexto, o esvaziamento de conteúdos e proclama-se o desenvolvimento "de habilidades, aptidões e valores apegados ao plano da imediaticidade [...] temperados com abstrações mistificadoras, deslocados de suas determinações ontológicas." (RABELO; MENDES SEGUNDO; JIMENEZ, 2009, p. 10). Assim, aqueles que têm acesso a essa 
educação de caráter eminentemente mercadológica são desprivilegiados quanto à formação intelectual humanística; tornam-se apenas e, quando muito, aptos ao mercado de trabalho, pois com as transformações constantes da inserção da ciência e da tecnologia na esfera produtiva, os parâmetros da chamada empregabilidade mudam com a mesma velocidade com que se aprofunda a crise do capitalismo contemporâneo.

Como se vê, os discursos das propostas da política educacional vigente apresentam a retórica que todos os indivíduos têm acesso a uma educação de qualidade. Porém, o que se percebe, na realidade, é um ensino restrito a treinamentos para execução de atividades setoriais diversas, voltadas ao mercado.

Enquanto planos, leis ${ }^{11}$ e propostas pedagógicas mascaram a realidade da educação brasileira, agudizando a precariedade existente no ensino do país, podemos verificar - ao contrário do discurso burguês da qualidade -, a existência de absurdas irregularidades no sistema de ensino, tais como: superlotação de salas de aula, falta de professores, baixos salários, estrutura física precária, desvio de verbas, dentre outras inúmeras dificuldades cotidianas.

Essas condições são refletidas no Relatório de Monitoramento Global de Educação para Todos 2008, intitulado: Educação para Todos em 2015: um objetivo acessível? $\left(\right.$ UNESCO, 2010) ${ }^{12}$, o qual apresenta índices qualitativos baixos com relação à educação básica no Brasil. O relatório afirma que a taxa de repetência, por exemplo, atinge um total de $18,7 \%$, superando os números do abandono escolar, que são de 13,8\%. Em meio a essas dificuldades, a diretora geral da Unesco, Irina Bokova nos diz que não se pode permitir o surgimento de uma "geração perdida" de crianças e jovens privadas da possibilidade de receber uma educação que lhes permitam sair da pobreza (UNESCO, 2010).

No plano legal, a Constituição Federal do Brasil de 1988 proclama que a educação é direito de todos e um dever do Estado. Porém, sendo o sistema educacional administrado por um Estado burguês, o processo educativo pende para o cumprimento das determinações do capital, favorecendo a classe dominante em detrimento dos trabalhadores. Nesse movimento, o Estado procura se eximir da responsabilidade para com a educação pública, gratuita, laica e de qualidade, deixando-a a cargo de iniciativas privatizantes (público-privadas), orientadas e monitoradas pelos organismos internacionais.

A respeito da política de atuação do Estado na educação, Jimenez e Mendes Segundo (2007, p. 125) refletem que este inclui formas "de negação do conhecimento, como o ensino a distância, a fragmentação dos currículos, a redução do tempo de duração dos cursos, ou treinamento docente em serviço", além disso, o Banco Mundial, interessado na inserção dos países pobres na almejada globalização e no desenvolvimento sustentável, argumenta que os preceitos de gestão devem ser implantados na administração dos recursos na educação, considerados suficientes pelo banco. Nessa direção, a normalização do Banco é a redução dos investimentos para o sistema público, recomendando o aligeiramento, a privatização, empresariamento e neopragmatismo no ensino, cabendo à educação "contribuir para a erradicação da pobreza, melhor dizendo, para a redução pela metade, da pobreza extrema." (JIMENEZ; MENDES SEGUNDO, 2007, p. 125).

Para melhor entendermos aquela constitucional prerrogativa do direito à educação é importante observarmos o texto da Declaração dos Direitos do Homem e do Cidadão, de 1789, que expressa: "estes escritos foram elaborados na intenção de apontar quais os direitos básicos de todos os membros que compõem a sociedade e, mediante a especificação destas leis, cobrar a efetivação das mesmas." De acordo o $6^{\circ}$ artigo:

Todos os cidadãos têm o direito de concorrer, pessoalmente ou através dos seus representantes, para a sua formação. Ela deve ser a mesma para todos, quer se destine a proteger quer a punir. Todos os cidadãos são 
iguais aos seus olhos, são igualmente admissíveis a todas as dignidades, lugares e empregos públicos, segundo a sua capacidade, e sem outra distinção que não seja a das virtudes e de seus talentos.

Não seria a lei - ao contrário do que está posto - a expressão da vontade da classe dominante, ou seja, da minoria? Como falar de igualdade para todos se o próprio sistema que rege a sociedade é desigual, reproduzindo tais desigualdades entre os homens? Ademais, não pode haver igualdade numa sociedade em que o processo, as ferramentas e o produto do trabalho não pertençam ao trabalhador e as relações de produção são pautadas na exploração do trabalho.

No tocante à educação, entendemos que é direito de todos o acesso ao ensino público gratuito, laico e de qualidade, não somente do ponto de vista do direito burguês, mas pelo fato de que a todo indivíduo - enquanto ser social - deve ser garantido os meios de partilhar o conhecimento historicamente acumulado pelo conjunto de homens e mulheres, tornando-se partícipe de seu gênero.

Sabemos, contudo, que embora prescrito tanto na Declaração dos Direitos do Homem e do Cidadão, quanto na última Constituição brasileira, de 1988, bem como em outras leis sancionadas, tanto em âmbito nacional e internacional, reiteram as políticas sociais, dentre elas a educação, como um direito universal e o dever do Estado. Entretanto, as políticas sociais burguesas - no quadro das desigualdades originárias da contradição capital-trabalho - estão impedidas de serem efetivadas, já que o direito formal burguês legitima a propriedade privada, a desigualdade e, com a crise do capital, a centralização das riquezas produzidas pela classe dominante.

Todavia, observamos que dentro da contradição de negação do conhecimento à classe trabalhadora, com total ausência de políticas públicas voltadas para a qualidade educacional efetiva, existe o interesse particular por uma generalização de oferta de escolarização para as populações em precariedade social. É atribuído ao processo educativo, portanto, uma função distinta da sua histórica importância, reduzindo a educação à capacitação técnica do trabalhador para que este venha a exercer, exclusivamente, funções laborais, necessárias, do lado do capital, ao processo acumulativo e, do lado do trabalhador, a garantia da sua própria subsistência. Destarte, para as agências multilaterais, a educação contemporânea deve assumir destacadamente o papel de reprodutora da ideologia burguesa.

Como assevera Leher (2010, p. 186) "a educação é [para os agentes internacionais] a principal variável da possibilidade de que um indivíduo ultrapasse a linha da pobreza", mesmo que o conhecimento seja substituído pelo caráter praticista, aligeirado e imediatista cumpridor do sujo papel ideológico e/ou estratégico que orienta as agências internacionais; ainda que essa retórica discursiva seja defendida poeticamente pelos intelectuais das agências internacionais, na esteira de Delors, como um "tesouro a descobrir".

\section{Considerações Finais}

Ao analisarmos alguns documentos da Educação para Todos e a disposição de limites em seus prazos para alcançar os resultados máximos em relação à aprendizagem e à universalização da educação básica para todos, assegurando, ao mesmo tempo, a tão almejada cidadania, precisamos pontuar algumas questões que consideramos importante para o desvelamento da lógica imposta as políticas educacionais nos países membros da Unesco, sobretudo, os países pobres, denominados em vulnerabilidade social. 
Inicialmente, podemos ponderar a constante prorrogação dos prazos ou a reedição das metas da EPT em eventos subsequentes, ano a ano, que nos aponta para a impossibilidade de concretização das metas pré-estabelecidas, haja vista que a lógica do capital em crise não permite a objetivação de alteração do quadro de pobreza e desigualdade. As metas, as datas e seus resultados são improváveis, contudo, os interesses dos organismos internacionais funcionam como moeda de troca e pressão ideológica sobre os países que se submetem a tal controle, uma vez que estes são pobres e dependentes dos parcos recursos captados das agências transnacionais.

Frente a esse debate, podemos verificar que o interesse essencial das prerrogativas de inúmeros encontros sobre educação ao redor do mundo é a reprodução do capitalismo em crise, via políticas socioeducativas. Os trabalhadores e seus filhos, nesse cenário, são instruídos de forma minimamente qualificada com conhecimentos fragmentados e apenas necessários à reprodução do sistema capitalista para, assim, atenderem às necessidades do mercado de trabalho no contexto do capital em crise estrutural.

Uma educação de qualidade que aponte para além da sociabilidade atual, que possa formar omnilateralmente, dista, pelo que temos visto com base na história, do interesse capitalista. Nos planos da burguesia, com efeito, inexiste a preocupação com a formação do homem livre, que apontaria, necessariamente, para uma sociedade realmente emancipada, atendendo aos reais anseios da classe trabalhadora, tal qual a educação omnilateral prescrita nos clássicos do marxismo, até mesmo porque, uma educação livre deve considerar uma sociedade absolutamente livre.

Em meio à intensificação das políticas internacionais de reformular os processos educativos dos países pobres, utilizando o falso argumento de "ajudar" o desenvolvimento interno sustentável, os quais promovem reformas pedagógicas que intentam favorecer a inserção imediata dos trabalhadores e seus filhos ao mercado de trabalho, o capitalismo usa o complexo educacional como um instrumento para sua perpetuação, utilizando, nesse propósito, a escola como um instrumento de empecilho ao projeto da emancipação humana.

Assim sendo, certificamos que, dentro da sociedade cindida em duas distintas classes sociais e que se encontra em crise crônica, a escola, mesmo gozando de autonomia relativa, mais do que nunca na sua história, tende a reproduzir e consolidar os interesses dominantes.

À educação sistematizada, oferecida no contexto da crise do capitalismo contemporâneo, em meio à intensificação das contradições sociais, interessa habilitar força laboral para servir ao mercado, negando o acesso dos trabalhadores aos benefícios produzidos pelo seu próprio trabalho, impossibilitando-os de desfrutar da cultura universal acumulada historicamente pelo conjunto da humanidade.

Percebemos que, mais uma vez na história, a burguesia recorre à educação, como mecanismo para instruir minimamente a classe explorada, ou seja, prover uma educação "em doses homeopáticas" aos trabalhadores, como afirmara Adam Smith. Desse modo, a meta de universalização da escolaridade básica recomendada pelo Programa de Educação para Todos e implantada por políticas de cunho socioeducativas a classe trabalhadora nos países pobres, se restringe aos paradigmas do aprender a aprender, sobretudo, do pilar do 'aprender a fazer', que se articula, no limite, ao ensino profissionalizante, em atendimento ao interesse do grande capital em crise profunda.

Todavia, mesmo imersos nesse quadro social de crise, em que se encontra o complexo educacional, cabe aos educadores na perspectiva de classe, desenvolver uma educação autônoma, crítica e que busque atividades emancipadoras, tal como assinala Tonet (2005), no objetivo de contribuir com a transformação radical da atual realidade 
societal do capital. Cônscios, todavia, das dificuldades de tal prática dentro do cenário de crise aguda do capitalismo contemporâneo, vislumbra-se a necessidade, dentro dos limites de cada situação histórica, de se construir espaços de resistência.

A escola, sobretudo a pública, é um desses espaços de contradições e de lutas, onde se deve pleitear a superação da presente sociedade exploradora, pois como temos dito, a relação capitalismo-educação não é determinista e mecânica, mas dialética, existe entre as duas uma zona de autonomia relativa. Todavia, reforçamos que, enquanto a educação servir, de forma preponderante, de instrumento de domínio para as classes hegemônicas, será impossível um ensino nos marcos da omnilateralidade, no âmbito da formação humana e revolucionária, proposto por Marx. Lutar por uma educação para a emancipação humana é lutar pela extinção do próprio capitalismo enquanto modelo de sociabilidade. Nessa perspectiva, importa-nos compreender agudamente esses entraves para que possamos combater coerentemente os fatores responsáveis pela crise da educação e da própria humanidade, onde a barbárie nos salta aos olhos cotidianamente.

\section{Referências}

BAVERMAN, H. Trabalho e capital monopolista: a degradação do trabalho no século XX. Rio de Janeiro: Guanabara, 1987.

DECLARAÇÃO dos Direitos do Homem e do Cidadão. França, 26 de agosto, 1789. Disponível em: <http://www.direitoshumanos.usp.br/.../declaracao-de-direitos-do-homeme-do-cidadao-1789.htm >. Acesso em: 30 nov. 2010.

DUARTE, Newton. As pedagogias do "aprender a aprender" e algumas ilusões da assim chamada sociedade do conhecimento. Revista Brasileira de Educação, n. 18, p. 35-40, set./dez. 2001. Disponível em: http://www.scielo.br/pdf/rbedu/n18/n18a04.pdf. Acesso em: 26 abr. 2013.

FARIAS, Aracelia C.; SANTOS, Deribaldo; FREITAS, Maria Cleidiane C.. Ensino médio integrado no Estado do Ceará: o "Caminho de pedras" do empreendedorismo em direção à escola pública. In: SANTOS, Deribaldo et al (Orgs.). Educação pública, formação profissional e crise do capitalismo contemporâneo. Fortaleza: EdUECE, 2013.

JIMENEZ, Susana; MENDES SEGUNDO, Maria das Dores. Erradicar a pobreza e reproduzir o capital: notas críticas sobre as diretrizes para a educação do novo milênio. Cadernos de educação, Pelotas, n. 28, p. 119-137, jan./jun. 2007.

LEHER, Roberto. Da Ideologia do Desenvolvimento à Ideologia da Globalização: a educação como estratégia do Banco Mundial para "Alivio" da Pobreza. 1998. Tese (Doutorado em Educação).Faculdade de Educação da Universidade de São Paulo FEUSP. São Paulo, 1998.

LEHER, Roberto. Um novo senhor da educação?: a política educacional do Banco Mundial para a periferia do capitalismo. Revista Outubro, n. 3, p. 19-30. Disponível em: <www.revistaoutubro.com.br/edicoes/03/out3 03.pdf >. Acesso em: $1^{\circ}$ out. 2010. 
LESSA, S. Trabalho e luta de classes na "sociedade do conhecimento". In: JIMENEZ, S. et al. Marxismo, educação e luta de classes: teses e conferências do II Encontro Regional Trabalho, Educação e Formação Humana. Fortaleza: EdUECE/IMO. 2008.

LUKÁCS, György. Para uma ontologia do ser social I. São Paulo: Boitempo, 2012.

MAIA FILHO, Osterne; JIMENEZ, Susana. A chave do saber: um exame crítico do novo paradigma educacional concebido pela ONU. In: SANTOS, Deribaldo et al (Orgs.). Educação pública, formação profissional e crise do capitalismo contemporâneo. Fortaleza: EdUECE, 2013.

MARX, Karl. O capital: crítica da economia política (livro primeiro, v. I). São Paulo: Civilização Brasileira, 2003.

MÉSZÁROS, István. Para além do capital. São Paulo: Boitempo, 2002.

O século XXI: socialismo ou barbárie. São Paulo: Boitempo, 2003.

ORGANIZAÇÃO DAS NAÇÕES UNIDAS PARA A EDUCAÇÃO, CIÊNCIA E CULTURA (Unesco). Educação para todos: o compromisso de Dakar. Senegal: Cúpula Mundial de Educação, 2000. Disponível em: <http://unesdoc.unesco.org/images/0012/001275/127509porb.pdf >. Acesso em: 16 ago. 2010.

Educação um tesouro a descobrir. Relatório para a Unesco da Comissão Internacional sobre Educação para o século XXI. Brasília: MEC; Cortez; Unesco, 1998. Disponível <http://www.dhnet.org.br/dados/.../r_unesco_educ_tesouro_descobrir.pdf >. Acesso em: 20 set. 2010.

Relatório de monitoramento de educação para todos Brasil 2008: educação para todos em 2015 - alcançaremos a meta? Brasília: Unesco, 2008. Disponível em: <http://unesdoc.unesco.org/images/0015/001592/159294por.pdf >. Acesso em: $1^{\mathrm{o}}$ set. 2010.

RABELO, Jackeline; MENDES SEGUNDO, Maria das Dores; JIMENEZ, Susana. Educação para todos e reprodução do capital. Revista Trabalho Necessário, Niterói: UFF, ano 7, n. 9, p. 1-24, 2009. Disponível em: < http://www.uff.br/trabalhonecessario/images/TN09\%20JIMENEZ,\%20S.\%20et\%20al.pdf >. Acesso em: 15 out. 2011.

RIO, Cristiane Porfirio. Baixos índices de proficiência no ensino básico público cearense: primeiras aproximações. In: SANTOS, Deribaldo et al (Orgs.). Educação pública, formação profissional e crise do capitalismo contemporâneo. Fortaleza: EdUECE, 2013.

SANTOS, Deribaldo. Graduação tecnológica no Brasil: crítica à expansão do ensino superior não universitário, 2009. Tese (Doutorado em Educação Brasileira) - Faculdade de Educação, Universidade Federal do Ceará, Fortaleza, 2009.

TONET, Ivo. Educação, cidadania e emancipação humana. Ijuí: Unijuí, 2005. 


\title{
VIEIRA PINTO, Álvaro. O conceito de tecnologia. Rio de Janeiro: Contrapontos, 2008.
}

\begin{abstract}
${ }^{1}$ Doutor em Educação pela Universidade Federal do Ceará (UFC). Professor da Faculdade de Educação, Ciências e Letras do Sertão Central da Universidade Estadual do Ceará (FECLESC /UECE). Professor do Curso de Mestrado Acadêmico Intercampi em Educação e Ensino (MAIE) e do Programa de Pós-Graduação em Educação (PPGE), da Universidade Estadual do Ceará (MAIE/PPGE/UECE). Pesquisador do Instituto de Estudos e Pesquisas do Movimento Operário da Universidade Estadual do Ceará (IMO/UECE). E-mail: deribaldo.santos@uece.br.

${ }^{2}$ Doutora em Educação pela Universidade Federal do Ceará (UFC). Professora da Faculdade de Filosofia Dom Aureliano Matos da Universidade Estadual do Ceará (FAFIDAM/UECE). Professora do Curso de Mestrado Acadêmico Intercampi em Educação e Ensino (MAIE) e do Programa de Pós-Graduação em Educação (PPGE), da Universidade Estadual do Ceará (MAIE/PPGE/UECE). Pesquisadora do Instituto de Estudos e Pesquisas do Movimento Operário da Universidade Estadual do Ceará (IMO/UECE). Email: mariadores.segundo@uece.br.

${ }_{3}$ Mestranda do Programa de Pós-Graduação em Educação (PPGE) da Universidade Estadual do Ceará (PPGE/UECE). Bolsista da CAPES. E-mail: cleidianecavalcante@ yahoo.com.br.

${ }^{4}$ Pedagoga do Centro de Referência da Assistência Social (CRAS). Especialização, em andamento, em Gestão Pública Municipal pela Universidade da Lusofonia Afro-Brasileira (UNILAB). E-mail: tayana_pedagogia@ hotmail.com

${ }^{5}$ Conforme indicam Farias, Freitas e Santos (2013), a sigla EPT é utilizada originalmente pelos organismos multilaterais para designar Educação Para Todos, todavia a literatura brasileira, sobretudo àquela ligada ao MEC, passou a usá-la como designação de Educação Profissional e Tecnológica.
\end{abstract}

${ }^{6}$ Para o filósofo Álvaro Vieira Pinto (2008), em função da evolução acentuada das bases materiais, sobretudo após a Segunda Guerra Mundial, com o crescimento acelerado da produção industrializada, a tecnologia passou a tomar assento no debate filosófico, assumindo, contudo, majoritariamente, uma posição deveras problemática. Rigorosamente, sustenta o autor, não se pode estudar a técnica sem posicioná-la dentro do valor fundamental e exato do seu locus: a tecnologia. Assim sendo, tecnologia é a teoria, a ciência, o estudo, a discussão, o debate da técnica. No entendimento mais comum e popular, todavia, a tecnologia aparece como sendo pura e simplesmente equivalente à técnica, ao conjunto de todas as técnicas ou, ainda, como sinônimo da variante americanizada, bastante recorrente no cotidiano, a charmosa expressão know how, ligada à coisa estrangeira, o que, por sua vez, transmite a ideia de tratar-se, irrevogavelmente de algo superior. Segundo Vieira Pinto (2008), há uma confusão conceitual praticada pela epistemologia burguesa que confere à técnica e à tecnologia papéis contrapostos e contraditórios. Se, por um lado, apresentam essas categorias como salvadoras maiores da humanidade, por outro, atribuem-lhes a culpa pelos maiores problemas existentes na contemporaneidade. O filosófico brasileiro considera que essas duas categorias são construções históricas da humanidade e, portanto, não possuem vida própria, dependem, outrossim, das contradições existentes na sociedade capitalista.

${ }^{7}$ Recorrendo a Lukács, Lessa (2008, p. 25-26) situa tais teses no quadro de um fenômeno ideológico típico do que o filósofo húngaro teria denominado de "o falso socialmente necessário". Esse fenômeno ocorreria "quando, numa dada conjuntura, há a necessidade de ideias rigorosamente falsas para se justificar uma dada formação social." Onde reside o poder dessas ideias, rigorosamente falsas, vale repetir, de aparentar a verdade? Para essa pergunta, Lessa $(2008$, p. 26) esclarece: "Como essas ideias se referem à vida cotidiana e aparentemente a explicam, elas terminam ganhando um estatuto de verdade."

${ }^{8}$ Para atender bem a ganância capitalista, o melhor é que esse ESNU seja custeado com programas de bolsas do erário público, a exemplo do Programa de Financiamento Estudantil (Fies) e do Programa Universidade para Todos (ProUni).

${ }^{9}$ Esta pesquisa se recusa a sinonimizar mercado de trabalho com mundo do trabalho. A primeira expressão não tem como abarcar o trabalho em sua função ontológica básica para a sociedade. A nosso ver, essa confusão apenas pode obscurecer e dificultar o real entendimento da problemática.

10 Na síntese crítica de Maia Filho e Jimenez (2013), os preceitos pedagógicos de Delors deveriam ser conhecidos pela sigla CHAVE (C de conhecimento; $\mathrm{H}$ de habilidade; A de atitude; V de valores e E de existencial). 
${ }^{11}$ Cada um a seu modo, dispositivos legais como, por exemplo, Plano Decenal de Educação para Todos (1993); Plano Nacional de Educação (PNE1 2001, PNE2 2011); Lei de Diretrizes e Bases da Educação Nacional (LDBEN) $n^{\circ} 9.394 / 96$, entre outros, acabam por sintetizar interesses das agências internacionais e dos empresários da educação.

12 Os Relatórios de Monitoramento Global de Educação para Todos (EPT) são documentos produzidos pela Unesco, em parceira com o Banco Mundial, que apresentam um diagnóstico nos países envolvidos, em relação ao cumprimento das metas e objetivos do programa de EPT. Nesse sentido, são reiterados ou reelaborados metas e prazos, focalizando uma temática, considerada mais problemática. Vale aqui enumerar as edições anteriores dos Relatórios de Monitoramento Global de EPT: A crise oculta: conflitos armados e educação (2011); Alcançar os Marginalizados (2010); Superando a desigualdade: por que a governança é importante (2009); Educação para Todos em 2015: um objetivo acessível? (2008); Bases sólidas: cuidados e educação na primeira infância (2007); Alfabetização: um desafio inadiável (2006); Educação para Todos: o imperativo da qualidade (2005); Gênero e educação para todos: o salto para a igualdade (2003/4); Educação para Todos: o mundo está no rumo certo? (2002). 